\title{
Maturational Changes in Rabbit Renal Brush Border Membrane Vesicle Osmotic Water Permeability
}

\author{
R. Quigley ${ }^{1}$, E.W. Harkins ${ }^{1}$, P.J. Thomas ${ }^{2}$, and M. Baum ${ }^{1,3}$ \\ ${ }^{1}$ Departments of Pediatrics University of Texas Southwestern Medical Center at Dallas, Dallas, \\ Texas 75235-9063, USA \\ 2Departments of Physiology University of Texas Southwestern Medical Center at Dallas, Dallas, \\ Texas 75235-9063, USA \\ ${ }^{3}$ Departments of Internal Medicine, University of Texas Southwestern Medical Center at Dallas, \\ Dallas, Texas 75235-9063, USA
}

\begin{abstract}
We have recently shown that the osmotic water permeability $\left(\mathrm{P}_{f}\right)$ of proximal tubules from neonatal rabbits is higher than that of adults (AJP 271:F871-F876, 1996). The developmental change in $\mathrm{P}_{f}$ could be due to differences in one or more of the components in the path for transepithelial water transport. The present study examined developmental changes in water transport characteristics of the proximal tubule apical membrane by determining $\mathrm{P}_{f}$ and aquaporin 1 (AQP1) expression in neonatal (10-14 days old) and adult rabbit renal brush border membrane vesicles (BBMV). AQP1 abundance in the adult BBMV was higher than the neonatal BBMV. At $25^{\circ} \mathrm{C}$ the $\mathrm{P}_{f}$ of neonatal BBMV was found to be significantly lower than the adult BBMV at osmotic gradients from 50 to $250 \mathrm{mOsm} / \mathrm{kg}$ water. The activation energy for osmotic water movement was higher in the neonatal BBMV than the adult BBMV $(9.19 \pm 0.37$ vs. $5.09 \pm 0.57$ $\left.\mathrm{kcal} \bullet \mathrm{deg}^{-1} \bullet \mathrm{mol}^{-1}, P<0.005\right)$. Osmotic water movement in neonatal BBMV was inhibited 17.9 $\pm 1.3 \%$ by $1 \mathrm{~m}_{\mathrm{M} \mathrm{HgCl}}$ compared to $34.3 \pm 3.8 \%$ in the adult BBMV $(P<0.005)$. These data are consistent with a significantly greater fraction of water traversing the apical membrane lipid bilayer in proximal tubules of neonates than adults. The lower $\mathrm{P}_{f}$ of the neonatal BBMV indicates that the apical membrane is not responsible for the higher transepithelial $\mathrm{P}_{f}$ in the neonatal proximal tubule.
\end{abstract}

\section{Introduction}

The mammalian proximal tubule is capable of isomotically reabsorbing $80 \%$ of the glomerular ultrafiltrate due to the high transepithelial osmotic water permeability $\left(\mathrm{P}_{f}\right)$ of this segment (Schafer, 1990). Aquaporin 1 (AQP1) is constitutively expressed in this nephron segment and is thought to be responsible, in part, for this high $\mathrm{P}_{f}$ (Sabolic et al., 1992; Nielsen et al., 1993). In the rat proximal tubule, there is a developmental increase in the expression of AQP1 (Bondy et al., 1993; Smith et al., 1993). Immunohistochemical staining 
of AQP1 in rat proximal tubule is minimal in stage III and stage IV nephrons three days prior to birth. By six days after birth, there is intense staining in both apical and basolateral membranes of the proximal tubule (Smith et al., 1993). Thus, because of its lower expression of AQP1, the newborn proximal tubule water permeability would be expected to be lower than that of the adult. However, we have recently directly examined the transepithelial water permeability in rabbit neonatal and adult proximal convoluted tubules and found $\mathrm{P}_{f}$ to be higher in neonatal tubules than adult tubules (Quigley \& Baum, 1996).

The route for transepithelial water transport is primarily transcellular across the apical and basolateral cell membranes and the intracellular compartment (Berry, 1983; Preisig \& Berry, 1985; Verkman, 1989). Because differences in transepithelial $\mathrm{P}_{f}$ could be due to maturational changes in one or more of the water transport pathway components, each component must be studied separately. Water transport through the cell membranes may occur either through the lipid bilayer or may be channel-mediated (Berry, 1983; Verkman, 1989; Agre et al., 1993; Verkman et al., 1996). Movement of water through the lipid bilayer is characterized by a high activation energy and is not affected by $\mathrm{HgCl}_{2}$, while channelmediated water transport is characterized by a low activation energy and is inhibitable by $\mathrm{HgCl}_{2}$ (Berry, 1983; Verkman, 1989). The intracellular compartment is thought to act as a complex unstirred layer and may account for $50 \%$ of the total resistance to water movement (Berry, 1985).

The purpose of the present study was to examine the developmental changes in the proximal tubule apical membrane osmotic water permeability. The approach taken was to examine osmotic water movement in brush border membrane vesicles (BBMV) from adult and neonatal rabbit renal cortex. The activation energy and the mercury sensitivity of osmotic water movement were examined to determine the mechanism for osmotic water movement through the neonatal and adult BBMV. Maturation of BBMV expression of AQP1 was examined by immunoblot analysis.

\section{Materials and Methods}

\section{Preparation of Brush Border Membrane Vesicles}

Brush border membrane vesicles were prepared from adult (>12 weeks old) or neonatal (815 days old) New Zealand white rabbits as previously described in our laboratory (Arar, Levi, \& Baum, 1994). Kidneys were removed from freshly sacrificed animals and kept in ice-cold PBS (in mM: $137 \mathrm{NaCl}, 2.7 \mathrm{KCl}, 10.1 \mathrm{Na}_{2} \mathrm{HPO}_{4}, 1.7 \mathrm{KH}_{2} \mathrm{PO}_{4}, \mathrm{pH} 7.4$ ) prior to dissection of cortex. Dissected tissue was divided into 1.5- to 2-gram portions which were placed immediately in 15-ml ice-cold isolation buffer (300 тм р-mannitol, 16 mм HEPES, 5 $\mathrm{m}_{\mathrm{M}}$ EGTA, adjusted to $\mathrm{pH} 7.5$ with Tris-HCl; $2 \mu \mathrm{g} / \mathrm{ml}$ each of aprotonin and leupeptin and $100 \mu \mathrm{g} / \mathrm{ml}$ phenylmethylsulfonyl fluoride were added immediately before use). Tissues were homogenized with 12 strokes using a Potter homogenizer at $4^{\circ} \mathrm{C}$. The homogenate was added to 20-ml of ice-cold water to induce hypotonic shock and $600 \mu \mathrm{l}$ of $1 \mathrm{M} \mathrm{MgCl}_{2}$ to precipitate cell debris. The homogenate was kept on ice for $20 \mathrm{~min}$, vigorously shaking for approximately $10 \mathrm{sec}$ every $5 \mathrm{~min}$ and then centrifuged $15 \mathrm{~min}$ at $2500 \times g, 4^{\circ} \mathrm{C}$. The supernatant was added to fresh centrifuge tubes containing $600 \mu \mathrm{l}$ of $1 \mathrm{M} \mathrm{MgCl}_{2}$, which was then shaken and centrifuged as before. The subsequent supernatant was then centrifuged for 
$30 \mathrm{~min}$ at $48,000 \times g, 4^{\circ} \mathrm{C}$. Pellets from a single adult animal or from one neonatal litter were combined and resuspended with a 20 -gauge needle in ice-cold resuspension buffer ( 5 $\mathrm{m}_{\mathrm{M}} \mathrm{HEPES}$, Tris- $\mathrm{HCl}$ to $\mathrm{pH} 7.5$, $\mathrm{D}-\mathrm{mannitol}$ to $80 \mathrm{mOsm} / \mathrm{kg}$ water) to a final concentration of approximately $10-20 \mathrm{mg}$ protein/ml (roughly $1-1.5 \mathrm{ml}$ per pair of adult kidneys) after which protein concentration was determined (BCA assay, Pierce). Alkaline phosphatase activity was measured in the crude homogenate and the BBMV preparation to assess the enrichment as previously described in our laboratory (Arar et al., 1994). There was no difference between the adult and neonatal BBMV alkaline phosphatase enrichment (Fold increase: Adult: $7.4 \pm 1.0 \mathrm{vs}$. Neonates: $6.6 \pm 0.7, P=\mathrm{NS}$ ).

Initial vesicle size was determined by transmission electron microscopy. Diameters were measured on vesicles from a randomly selected sample of greater than 200 vesicles each for adult and neonate.

\section{Immunoblotting for AQP1}

Immunoblots for AQP1 were performed by loading $20 \mu \mathrm{g}$ total protein of neonatal and adult BBMV in final volume of $30 \mu \mathrm{l}$ of loading buffer (1.7 mм Tris, pH 6.8, $1 \%$ SDS, $10 \%$ glycerol, 1\% 2-mercaptoethanol, pinch bromphenol blue) in each sample lane, with a separate lane containing $20 \mu$ Prestained Molecular Weight Standards (\#SDS-7B, Sigma). Proteins were transferred onto PVDF (Immobilon) overnight at $4^{\circ} \mathrm{C}$ using Bio-Rad Transblot electroblotting apparatus.

Anti-AQP1 (Alomone Labs, Jerusalem, Israel) was used at 1: 1,000, anti- $\beta$-actin (Sigma) at 1:5,000, and HRP-conjugated anti-rabbit monoclonal Ab (Amersham ECL kit) was used at 1:10,000. All antibodies were diluted in Blotto (5\% nonfat dried milk, $0.05 \%$ Tween-20 in autoclaved Phosphate Buffered Saline (PBS containing (in $\mathrm{mM}$ ): $150 \mathrm{NaCl}, 10$ sodium phosphate, $2.6 \mathrm{KCl}$ and $1 \mathrm{KH}_{2} \mathrm{PO}_{4} ; \mathrm{pH}$ 7.4). Labeling and detection were done at room temperature on a rotator. Blots were wetted briefly in methanol, rinsed in $\mathrm{H}_{2} \mathrm{O}$ and PBSTween (0.05\% Tween-20), preincubated in Blotto for $1 \mathrm{hr}$ and incubated with the primary antibody for $2 \mathrm{hr}$ at room temperature. Blots were then rinsed 3 times over $30 \mathrm{~min}$ in PBSTween (1\% Tween-20), incubated in secondary $\mathrm{Ab}$ for $1 \mathrm{hr}$ and washed 3 times over $30 \mathrm{~min}$. Detection was done with Amersham ECL kit.

\section{Rapid Kinetics for Water Permeability $\left(P_{f}\right)$ Measurement}

Fluorescein Loading-Vesicle shrinkage was followed using fluorescence quenching of an entrapped fluorophore as described by Chen, Pearce, and Verkman (1988). Briefly, immediately following protein assay (see vesicle preparation) vesicles were brought to 10 $\mathrm{mg}$ protein/ml in $80 \mathrm{mOsm}$ resuspension buffer containing $10 \mathrm{~m}_{\mathrm{M}}$ fluorescein-5-(and-6)sulfonic acid (Molecular Probes, Eugene, OR) overnight at $4{ }^{\circ} \mathrm{C}$ in the dark. Loaded vesicles were washed by dilution in $80 \mathrm{mOsm}$ resuspension buffer and ultracentrifugation (4 times at a dilution of $>19$-fold for $10 \mathrm{~min}$ at $368,000 \times \mathrm{g}, 4^{\circ} \mathrm{C}$ ). Each pellet was resuspended with both 22-and a 25 -gauge needles. Vesicles were resuspended at a final concentration of 0.6$\mathrm{mg}$ protein $/ \mathrm{ml}$ in $80 \mathrm{mOsm}$ resuspension buffer, and were used within 2 to $3 \mathrm{hr}$ after preparation. 
Stop-Flow Kinetics-Because of the speed of water movement across the brush border membrane vesicles, these experiments required rapid mixing with a stop-flow device. The stopped flow apparatus (SFM-3, BioLogic, dead time $\sim 7.5 \mathrm{msec}$ ) was set to mix $100 \mu \mathrm{l}$ of vesicles 1:1 (final concentration of $0.3 \mathrm{mg}$ protein $/ \mathrm{ml}$ ) with resuspension buffer of the desired osmolality (as above, adjusting the osmolality with $\mathrm{D}$-mannitol). Excitation was from a 75-watt xenon arc lamp via a monochrometer set at $470 \mathrm{~nm}$ and emission was measured via monochrometer set at $515 \mathrm{~nm}$ using Photon Technology Incorporated (PTI) fluorometer. The fluorometer was interfaced to the mixing device via randomly wound, fused-silica fiber optic cables. Data were collected in photon counting mode at 250 points/second for $2 \mathrm{sec}$ using PTI software. For each experiment, 10 raw tracings were collected and averaged for subsequent analysis. To avoid increased dye leakage reported at higher temperatures (Chen et al., 1988), vesicles were kept on ice prior to use.

Light Scattering-To determine the mercury sensitivity of osmotic water permeability, vesicle volume was followed with light scattering at $25^{\circ} \mathrm{C}$ (van Heeswijk \& van Os, 1986; Meyer \& Verkman, 1987). The procedure was similar to the fluorescence experiments except that the excitation and emission wave lengths were set at $400 \mathrm{~nm}$. These experiments were performed on fresh vesicles at an initial concentration of $0.6 \mathrm{mg}$ protein $/ \mathrm{ml}$. The vesicles were incubated with $1 \mathrm{~m} \mathrm{M} \mathrm{HgCl}_{2}$ for $10 \mathrm{~min}$ at room temperature prior to mixing with the hypertonic solution. The final osmotic gradient for these experiments was 150 $\mathrm{mOsm} / \mathrm{kg}$ water. To examine if the effect of $\mathrm{HgCl}_{2}$ was reversible, vesicles were incubated in $10 \mathrm{~m}_{м} \beta$-mercaptoethanol for $30 \mathrm{~min}$ at room temperature after incubating with $\mathrm{HgCl}_{2}$.

\section{Results \\ Immunoblot for AQP1}

Figure 1 shows the immunoblot of AQP1 and $\beta$-actin in both the neonatal and adult BBMV. The ratio of AQP1 abundance/ $\beta$-actin abundance from the densitometric measurements was significantly higher in the adult BBMV than that in the neonate (Adult $(n=4) 0.24 \pm 0.04$ $v s$. Neonate $(n=3) 0.11 \pm 0.02, P<0.05)$. Thus, there is a maturational increase in the expression of AQP1 in the rabbit proximal tubule apical membrane.

\section{Initial Vesicle Size}

Initial vesicle size was measured using transmission electron microscopy. There was no significant difference observed between adult $(n=210)$ and neonatal $(n=220)$ initial vesicle diameter (adult: $202.2 \pm 6.7 \mathrm{~nm} v s$. neonate: $192.0 \pm 5.1 \mathrm{~nm} P=\mathrm{NS}$ ). Thus, any difference in the calculated $\mathrm{P}_{f}$ is not due to a difference in the initial vesicle size.

\section{Fluorescence Data}

Rate Constants-BBMV osmotic water permeability was examined by following the time course of fluorescence quenching of an entrapped fluorophore, fluorescein sulfonate, as described by Chen et al. (1988). These experiments were performed at $25^{\circ} \mathrm{C}$. The fluorescence data were normalized by the initial fluorescence and fit to a single exponential curve using the simplex method (Biokine Software, Molecular Kinetics; Pullman, Washington). Figure 2 compares a typical tracing of an adult and a neonatal preparation 
using the $250 \mathrm{mOsm} / \mathrm{Kg}$ gradient. As can be seen, the rate of shrinkage for the adult BBMV is faster than the neonatal BBMV. The Table shows the rate constants for the adult and neonatal BBMV for the four concentration gradients examined. At the $50 \mathrm{mOsm}$ gradient, although the neonatal rate constant tended to be lower than the adult, the difference was not statistically significant. However, at the three higher concentration gradients, the neonatal rate constants were significantly lower than the adult values, indicating that the osmotic water permeability in the neonatal BBMV was less than that in the adult.

Fluorescence to Size Transformation-Although the raw fluorescence data indicate that the neonatal BBMV have slower osmotic water movement than the adult BBMV, to calculate and compare the osmotic water permeability coefficients $\left(\mathrm{P}_{f}\right)$ requires transforming the relative fluorescence data to relative size. To determine the correlation between relative fluorescence and relative size of the vesicles, the equilibrium value for fluorescence (after the vesicles have shrunk) was compared to the calculated degree of shrinkage. BBMV have previously been shown to behave as perfect osmometers in this range of osmolalities (Verkman, Dix \& Seifter, 1985; Beck, Lipkowitz \& Abramson, 1988). Figure $3 a$ shows the relationship between the asymptote and the ratio of $\mathrm{Osm}_{\mathrm{ou}} \mathrm{t} / \mathrm{Osm}_{\mathrm{in}}$. There was no difference between the adult and neonatal values, so they were combined to fit the transformation:

$$
\text { Size }=\frac{c}{a \cdot \text { Fluorescence }+b} \text {, }
$$

where $a, b$ and $c$ are arbitrary parameters from fitting the data. Figure $3 b$ shows the fit between the fluorescence and size.

This transformation was applied to the raw fluorescence data to convert the relative fluorescence to relative size. Figure 4 shows the same tracings from Fig. 2 after the data were transformed.

$\mathbf{P}_{\mathbf{f}}$ Calculation-The osmotic water permeability was calculated from the stop-flow data by two methods. The results are consistent with the $\mathrm{P}_{f}$ of neonatal BBMV being less than that of the adult BBMV at all osmotic gradients tested.

Figure $5 A$ shows the result from fitting the transformed data with a double exponential fit, then calculating $\mathrm{P}_{f}$ from the mean rate constant as described by van Heeswijk and van Os (1986). The equation used to calculate $\mathrm{P}_{f}$ was:

$$
k=\overline{V_{w}} P_{f}\left(A / V_{0}\right) C_{m},
$$

where $\overline{V_{w}}$ is the molar water volume, $A / V_{0}$ is the surface area to initial vesicle volume ratio and $C_{m}$ is the osmolality of the extravesicular solution.

Figure $5 B$ shows the result of fitting the transformed data with the second order kinetics equation:

$$
\operatorname{Size}(t)=a \cdot t+b+\frac{c}{1+d \cdot t}
$$


where $a, b, c$, and $d$ are parameters from fitting the data. The calculation of $\mathrm{P}_{f}$ from the second order kinetic equation was made by determining the initial slope of the curve.

\section{Activation Energy}

To determine the activation energy for osmotic water permeability, adult and neonatal BBMV were exposed to a $150 \mathrm{mOsm} / \mathrm{kg}$ water osmotic gradient with mannitol at temperatures from 17 to $39^{\circ} \mathrm{C}$. The raw fluorescence data were fit to a single exponential curve and an Arrhenius plot was constructed using the natural logarithm of the rate constants. Figure 6 shows the results. The activation energies (calculated from the slopes of the lines) were $9.19 \pm 0.37 \mathrm{kcal} \cdot \mathrm{deg}^{-1} \bullet \mathrm{mol}^{-1}$ for the neonates and $5.09 \pm 0.57 \mathrm{kcal} \bullet$ $\mathrm{deg}^{-1} \bullet \mathrm{mol}^{-1}$ for the adults $(P<0.005)$. The higher activation energy in the neonatal BBMV suggests that a higher fraction of water movement through the membrane may be through the lipid bilayer.

\section{Inhibition with mercury Chloride}

To determine the degree to which mercury can inhibit water transport, BBMV were incubated with $1 \mathrm{~mm} \mathrm{HgCl}_{2}$ and subjected to a $150 \mathrm{mOsm} / \mathrm{kg}$ water osmotic gradient at $25^{\circ} \mathrm{C}$. The size of the vesicles was followed with light scattering. Figure 7 shows a typical tracing of a neonatal $(B)$ and adult $(A) \mathrm{BBMV}$ preparation. As can be seen, $\mathrm{HgCl}_{2}$ had a smaller effect on $\mathrm{P}_{f}$ in neonatal than adult BBMV. The first $300 \mathrm{msec}$ of each curve was fit with a single exponential and $\mathrm{P}_{f}$ was calculated from the rate constant (van Heeswijk \& van Os, 1986). The percent inhibition was greater in the adult BBMV than the neonatal BBMV $(34.3 \pm 3.8 \%, n=11, v s .17 .9 \pm 1.3 \%, n=7, P<0.005)$. In both adult and neonatal BBMV the inhibition with $\mathrm{HgCl}_{2}$ was completely reversible with $\beta$-mercaptoethanol. This is consistent with less channel mediated water transport in the neonatal BBMV than the adult.

\section{Discussion}

The present study examined the maturation of rabbit renal brush border membrane vesicle osmotic water permeability. The $\mathrm{P}_{f}$ of BBMV from neonatal rabbits was found to be lower than that of adult BBMV. The activation energy for $\mathrm{P}_{f}$ in the neonatal BBMV was higher than the adult BBMV indicating that in the neonatal membrane, the fraction of water transported via diffusion through the lipid bilayer is higher than that in the adult. The amount of water transport in the neonatal BBMV that was inhibitable by mercury was approximately $50 \%$ of that in the adult BBMV. This is also consistent with more water transport in the neonatal membranes occurring through the lipid bilayer. The abundance of AQP1 in the neonatal BBMV was also significantly lower than the adult. Thus, the higher transepithelial $\mathrm{P}_{f}$ for neonatal proximal tubules previously found using in vitro microperfusion (Quigley \& Baum, 1996) cannot be explained by a higher $\mathrm{P}_{f}$ in the apical membrane.

The proximal tubule reabsorbs the bulk of the glomerular ultrafiltrate by a process that is nearly isoosmotic (Schafer, 1990). Because of the high transepithelial osmotic water permeability of this segment, large volume flows can be obtained with small osmotic gradients. It is thought that active transport of solute leads to hypotonicity of the luminal 
fluid and provides the driving force for this fluid movement (Schafer, 1990). In adult proximal tubules, the route for transepithelial water transport is thought to be transcellular, although this remains controversial (Preisig \& Berry, 1985; Schafer, 1990). While this issue has not been directly addressed in neonatal tubules, we have previously shown that solute reflection coefficients in both adult and neonatal proximal tubules perfused in vitro are not different from one (Quigley \& Baum, 1996). This suggests that water movement through the paracellular pathway is minimal. The transcellular route for water movement includes the apical and basolateral membranes and the intracellular compartment. Water movement through the cell membranes can occur by diffusion of water through the lipid bilayer or by transport through specific water channels. Thus, any differences in transepithelial water permeability must be due to differences in one or more of these components.

The rate at which water can move through the lipid bilayer is markedly influenced by the phospholipid and cholesterol composition of the membrane (Finkelstein \& Cass, 1967; Bittman \& Blau, 1972; Jain, Touissaint, \& Cordes, 1973; Fettiplace, 1978; Fettiplace \& Haydon, 1980; Haines, 1994). In artificial membranes, initial studies (Finkelstein \& Cass, 1967) indicated that an increase in the molar fraction of cholesterol decreased the membrane $\mathrm{P}_{f}$, however, subsequent studies (Bittman \& Blau, 1972; Jain, Touissaint \& Cordes, 1973) indicate that the cholesterol-phospholipid interaction is complex and results in a biphasic response to an increase in cholesterol content. The nature of the phospholipid component also greatly influences the membrane $\mathrm{P}_{f}$ (Fettiplace, 1978). In contrast to the artificial membranes, the osmotic water permeability of BBMV from aged rats (24 months old) is not different from normal adult rats (10 months old) despite a $15 \%$ increase in their cholesterol content (Pratz, Ripoche \& Corman, 1987). Thus, the importance of the cholesterol content to functional water transport in cellular membranes remains unclear.

Although developmental changes in rabbit renal BBMV cholesterol and phospholipid content have not been completely characterized, changes in membrane fluidity have been studied. Membrane fluidity, measured by fluorescence anisotropy of 1,6-diphenyl-1,3,5hexatriene (DPH), is higher in neonatal rabbit and rat renal BBMV than adult BBMV (Hise \& Weinman, 1986; Medow \& Segal, 1987; Beck et al., 1988). In rat intestinal BBMV, membrane fluidity was higher in the neonate than the adult; however, when the vesicles were reconstituted without the protein component, there was no difference in fluidity (Schwarz et al., 1985). Thus, these data suggest a protein-lipid interaction that contributes to the changes in fluidity.

The activation energy for water movement through membranes is lower for transport through aqueous pores $\left(<6 \mathrm{kcal} \bullet \mathrm{deg}^{-1} \bullet \mathrm{mol}^{-1}\right)$ than through the lipid bilayer $(>10 \mathrm{kcal} \bullet$ $\mathrm{deg}^{-1} \cdot \mathrm{mol}^{-1}$ ) (Verkman et al., 1996). In the present study, the activation energy for osmotic water movement in renal BBMV from neonatal and adult rabbits was determined. The result for the adult BBMV $\left(5.09 \pm 0.57 \mathrm{kcal} \cdot \mathrm{deg}^{-1} \cdot \mathrm{mol}^{-1}\right)$ is low enough to suggest that the route for water movement is primarily via water channels (Berry, 1983; Verkman, 1989; Verkman et al., 1996). The activation energy for the neonatal BBMV was found to be much higher $\left(9.19 \pm 0.37 \mathrm{kcal} \cdot \mathrm{deg}^{-1} \cdot \mathrm{mol}^{-1}\right)$. Although this is lower than the activation energy found in pure phospholipid bilayers, it is high enough to suggest that in neonatal BBMV, the fraction of water transport through the lipid portion of the membrane is higher 
than in adult BBMV (Berry, 1983; Verkman, 1989; Verkman et al., 1996). It is interesting to note that although the $\mathrm{P}_{f}$ for the neonatal BBMV is significantly lower than that of the adult at $25^{\circ} \mathrm{C}$, there is no difference at $39^{\circ} \mathrm{C}$. This suggests that although expression of AQP1 may be lower in young animals, osmotic water permeability in the proximal tubule may not be different at normal body temperature.

Water transport through AQP1 is mercury sensitive due to a cysteine residue at position 189 (Preston et al., 1993; Zhang et al., 1993). In the present study, osmotic water transport was inhibited to a smaller degree in the neonatal BBMV than the adult. This is consistent with a larger portion of the water movement being through the lipid bilayer in the neonatal membranes than the adult. In both preparations, the inhibition with $\mathrm{HgCl}_{2}$ was completely reversed with $\beta$-mercaptoethanol, consistent with reversible binding of mercury to AQP1.

We have recently demonstrated that the transepithelial $\mathrm{P}_{f}$ is higher in rabbit neonatal proximal tubules than adults (Quigley \& Baum, 1996). The present study shows that the $\mathrm{P}_{f}$ of the apical membrane in neonatal proximal tubules is lower than the adult and therefore may not be responsible for the higher transtubular $\mathrm{P}_{f}$. The other two components of the transcellular pathway that could potentially be responsible for the previous finding are the basolateral membrane and the intracellular compartment. AQP1 has been localized to both apical and basolateral membranes of the adult proximal tubule (Nielsen et al., 1993; Nielsen et al., 1995). In neonatal rats, AQP1 expression is also distributed in both apical and basolateral membranes of the proximal tubule (Smith et al., 1993). Although the basolateral membrane in adult rabbits and rats has a slightly higher $\mathrm{P} f$ than the brush border membrane, it is approximately the same magnitude (Verkman \& Ives, 1986; Meyer \& Verkman, 1987; Van der Goot, Podevin \& Corman, 1989).

The remaining component in the transcellular route for water movement is the intracellular compartment. The contribution of the cytoplasmic compartment to the transepithelial $\mathrm{P}_{f}$ has recently been shown to be a complex unstirred layer (Berry \& Verkman, 1988) and may account for over $50 \%$ of the transcellular resistance to water movement (Berry, 1985). Thus, small changes in the cellular compartment may have large effects on the transepithelial water permeability. The cell height in neonatal proximal tubules is significantly lower than adult proximal tubules (Evan, Gattone II \& Schwartz, 1983; Baum, 1990). This suggests that the path length for water movement through the cell may be much shorter in the neonatal proximal tubule than the adult. Thus, the higher transepithelial $\mathrm{P}_{f}$ in neonatal proximal tubules may be due to developmental changes in the intracellular compartment.

The present study examined maturation of the apical membrane $\mathrm{P}_{f}$ from rabbit renal cortex. There was a developmental increase in AQP1 expression. The $\mathrm{P}_{f}$ in neonatal BBMV was lower than the adult BBMV at $25^{\circ} \mathrm{C}$. There was also a larger activation energy and less inhibition with mercury chloride. Thus, the movement of water in the neonatal proximal tubule apical membrane is more lipid-mediated and less channel-mediated than the adult membrane. The reason for the higher transepithelial $\mathrm{P}_{f}$ in the neonatal tubules is probably due to differences in the intracellular compartment. 


\section{Acknowledgments}

This work was supported by National Institutes of Diabetes and Digestive and Kidney Diseases Grants K08DK02232 (RQ) and RO1-DK41612 (MB). We wish to thank Janell McQuinn for her able secretarial assistance and Vangipuram Dwarakanath for his technical assistance.

\section{References}

Agre P, Preston GM, Smith BL, Jung JS, Raina S, Moon C, Guggino WB, Nielsen S. Aquaporin CHIP: the archetypal molecular water channel. Am. J. Physiol. 1993; 265:F463-F476. [PubMed: 7694481]

Arar M, Levi M, Baum M. Maturational effects of glucocor-ticoids on neonatal brush-border membrane phosphate transport. Pediatr. Res. 1994; 35:474-478. [PubMed: 8047384]

Baum M. Neonatal rabbit juxtamedullary proximal convoluted tubule acidification. J. Clin. Invest. 1990; 85:499-506. [PubMed: 2153709]

Beck JC, Lipkowitz MS, Abramson RG. Characterization of the fetal glucose transporter in rabbit kidney: comparison with the adult brush border electrogenic $\mathrm{Na}^{+}$-glucose symporter. J. Clin. Invest. 1988; 82:379-387. [PubMed: 3403709]

Berry CA. Water permeabilities and pathways in the proximal tubule. Am. J. Physiol. 1983; 245:F279-F294. [PubMed: 6351634]

Berry CA. Characteristics of water diffusion in the rabbit proximal convoluted tubule. Am. J. Physiol. 1985; 249:F729-F738. [PubMed: 2998205]

Berry CA, Verkman AS. Osmotic gradient dependence of osmotic water permeability in rabbit proximal convoluted tubule. J. Membrane Biol. 1988; 105:33-43. [PubMed: 2852255]

Bittman R, Blau L. The phospholipid-cholesterol interaction. Kinetics of water permeability in liposomes. Biochemistry. 1972; 11:4831-4839. [PubMed: 4655255]

Bondy C, Chin E, Smith BL, Preston GM, Agre P. Developmental gene expression and tissue distribution of the CHIP28 water-channel protein. Proc. Natl. Acad. Sci. USA. 1993; 90:4500-4504. [PubMed: 8506291]

Chen PY, Pearce D, Verkman AS. Membrane water and solute permeability determined quantitatively by self-quenching of an entrapped fluorophore. Biochemistry. 1988; 27:5713-5718. [PubMed: 3179272]

Evan AP, Gattone II VH, Schwartz GJ. Development of solute transport in rabbit proximal tubule. II. Morphologic segmentation. Am. J. Physiol. 1983; 245:F391-F407. [PubMed: 6614177]

Fettiplace R. The influence of the lipid on the water permeability of artificial membranes. Biochim. Biophys. Acta. 1978; 513:1-10. [PubMed: 718883]

Fettiplace R, Haydon DA. Water permeability of lipid membranes. Physiol. Rev. 1980; 60:510-550. [PubMed: 6992166]

Finkelstein A, Cass A. Effect of cholesterol on the water permeability of thin lipid membranes. Nature. 1967; 216:717-718. [PubMed: 6082492]

Haines TH. Water transport across biological membranes. FEBS Lett. 1994; 346:115-122. [PubMed: 8206149]

van Heeswijk MPE, van Os CH. Osmotic water permeabilities of brush border and basolateral membrane vesicles from rat renal cortex and small intestine. J. Membrane Biol. 1986; 92:183-193. [PubMed: 3761362]

Hise MK, Weinman EJ. Physical properties of the renal brush border membrane during growth. Pfluegers Arch. 1986; 406:234-236. [PubMed: 3008076]

Jain MK, Touissaint DG, Cordes EH. Kinetics of water penetration into unsonicated liposomes: effects of n-alkanols and cholesterol. J. Membrane Biol. 1973; 14:1-16. [PubMed: 4798004]

Medow MS, Segal S. Age related changes in fluidity of rat renal brushborder membrane vesicles. Biochem. Biophys. Res. Commun. 1987; 142:849-856. [PubMed: 3827904]

Meyer MM, Verkman AS. Evidence for water channels in renal proximal tubule cell membranes. J. Membrane Biol. 1987; 96:107-119. [PubMed: 3599063] 
Nielsen S, Pallone T, Smith BL, Christensen EI, Agre P, Maun-sbach AB. Aquaporin-1 water channels in short and long loop descending thin limbs and in descending vasa recta in rat kidney. Am. J. Physiol. 1995; 268:F1023-F1037. [PubMed: 7541952]

Nielsen S, Smith BL, Christensen EI, Knepper MA, Agre P. CHIP28 water channels are localized in constitutively water-permeable segments of the nephron. J. Cell. Biol. 1993; 120:371-383. [PubMed: 7678419]

Pratz J, Ripoche P, Corman B. Cholesterol content and water and solute permeabilities of kidney membranes from aging rats. Am. J. Physiol. 1987; 253:R8-R14. [PubMed: 3605393]

Preisig PA, Berry CA. Evidence for transcellular osmotic water flow in rat proximal tubules. Am. J. Physiol. 1985; 249:F124-F131. [PubMed: 4014469]

Preston GM, Jung JS, Guggino WB, Agre P. The mercury-sensitive residue at cysteine 189 in the CHIP28 water channel. J. Biol. Chem. 1993; 268:17-20. [PubMed: 7677994]

Quigley R, Baum M. Developmental changes in rabbit juxta-medullary proximal convoluted tubule water permeability. Am. J. Physiol. 1996; 271:F871-F876. [PubMed: 8898017]

Sabolic I, Valenti G, Verbavatz J-M, Van Hoek AN, Verkman AS, Ausiello DA, Brown D. Localization of the CHIP28 water channel in rat kidney. Am. J. Physiol. 1992; 263:C1225-C1233. [PubMed: 1282299]

Schafer JA. Transepithelial osmolality differences, hydraulic conductivities, and volume absorption in the proximal tubule. Annu. Rev. Physiol. 1990; 52:709-726. [PubMed: 2184773]

Schwarz SM, Hostetler B, Ling S, Mone M, Watkins JB. Intestinal membrane lipid composition and fluidity during development in the rat. Am. J. Physiol. 1985; 248:G200-G207. [PubMed: 3970201]

Smith B, Baumgarten R, Nielsen S, Raben D, Zeidel MI, Agre P. Concurrent expression of erythroid and renal aquaporin CHIP and appearance of water channel activity in perinatal rats. J. Clin. Invest. 1993; 92:2035-2041. [PubMed: 8408657]

Van der Goot FG, Podevin R-A, Corman BJ. Water per-eabilities and salt reflection coefficients of luminal, basolateral and intracellular membrane vesicles isolated from rabbit kidney proximal tubule. Biochim. Biophys. Acta. 1989; 986:332-340. [PubMed: 2590675]

Verkman AS. Mechanisms and regulation of water permeability in renal epithelia. Am. J. Physiol. 1989; 257:C837-C850. [PubMed: 2688434]

Verkman AS, Dix JA, Seifter JL. Water and urea transport in renal microvillus membrane vesicles. Am. J. Physiol. 1985; 248:F650-F655. [PubMed: 3993788]

Verkman AS, Ives HE. Water permeability and fluidity of renal basolateral membranes. Am. J. Physiol. 1986; 250:F633-F643. [PubMed: 3963203]

Verkman AS, Van Hoek AN, Ma T, Frigeri A, Skach WR, Mitra A, Tamarappoo BK, Farinas J. Water transport across mammalian cell membranes. Am. J. Physiol. 1996; 270:C12-C30. [PubMed: 8772426]

Zhang R, Van Hoek AN, Biwersi J, Verkman AS. A point mutation at cysteine 189 blocks the water permeability of rat kidney water channel CHIP28k. Biochemistry. 1993; 32:2938-2941. [PubMed: 8457558] 

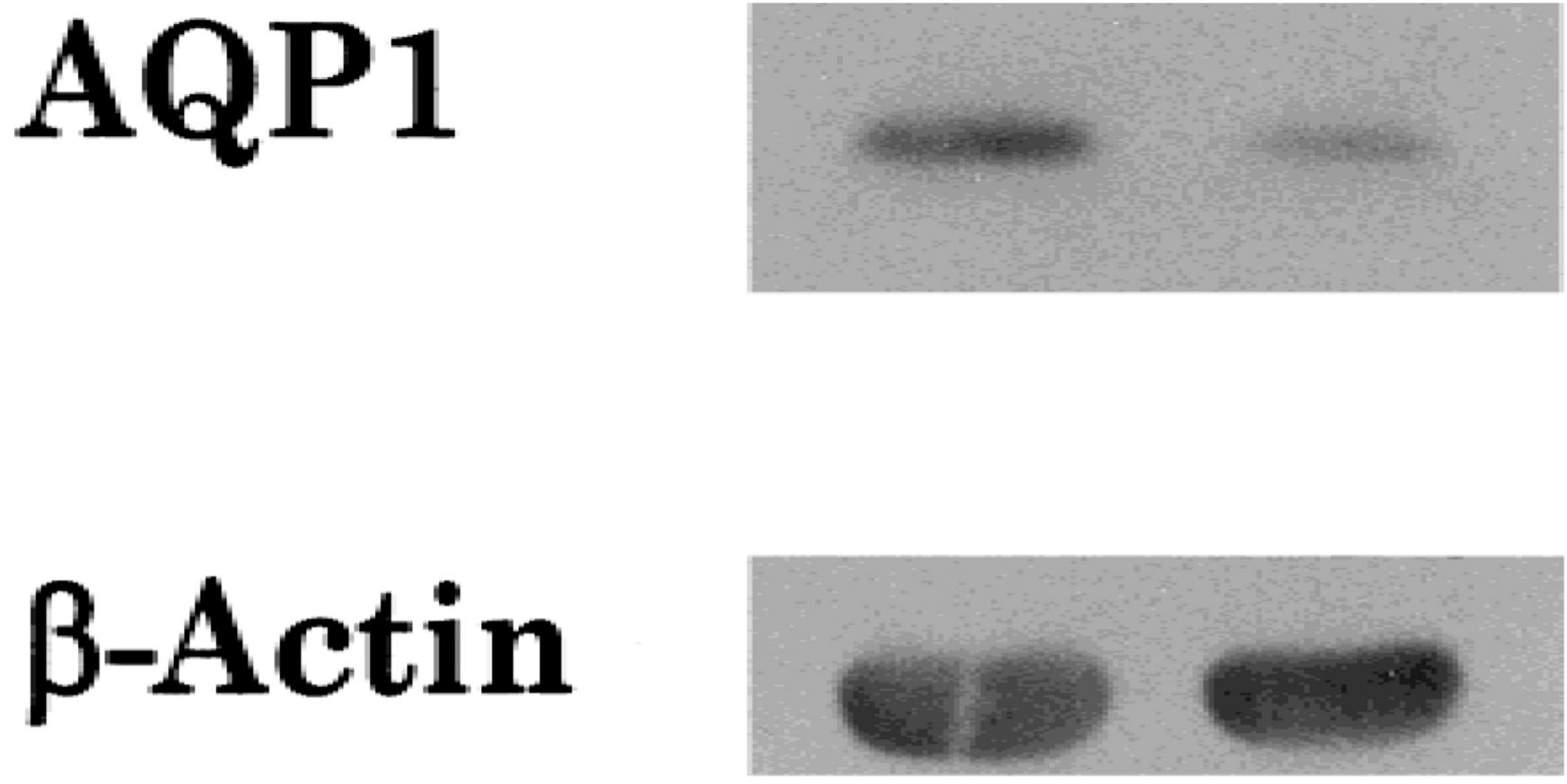

\section{Adult Neonatal}

Fig. 1.

Immunoblot of AQP1 abundance in neonatal and adult BBMV. Each lane was loaded with $20 \mu \mathrm{g}$ of total protein and probed with anti-AQP1 antibody. Densitometry demonstrated a higher abundance in the adult BBMV than the neonate. 


\section{Adult and Neonatal BBMV}

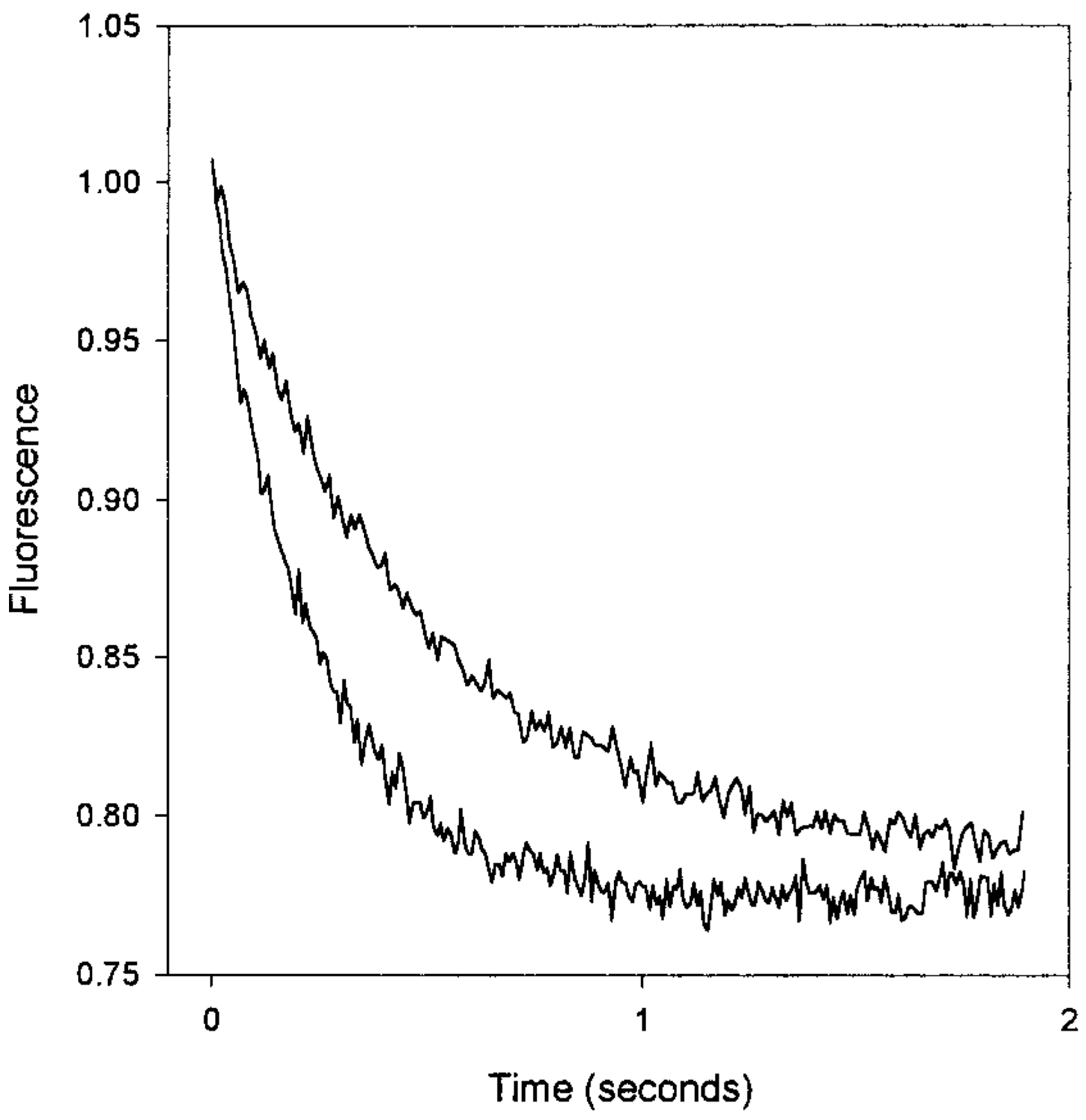

Fig. 2.

Relative fluorescence of neonatal (upper curve) and adult (lower curve) BBMV. Vesicles were loaded with $10 \mathrm{~m}_{\mathrm{M}}$ fluorescein-sulfonate in resuspension buffer $(80 \mathrm{mOsm} / \mathrm{kg}$ water) and exposed to an inwardly directed osmotic gradient ( $250 \mathrm{mOsm} / \mathrm{kg}$ water). Vesicle shrinkage results in fluorescence quenching. Fluorescence curves were fit with a single exponential. 
A

Relative Fluorescence vs. Osmolality Ratio

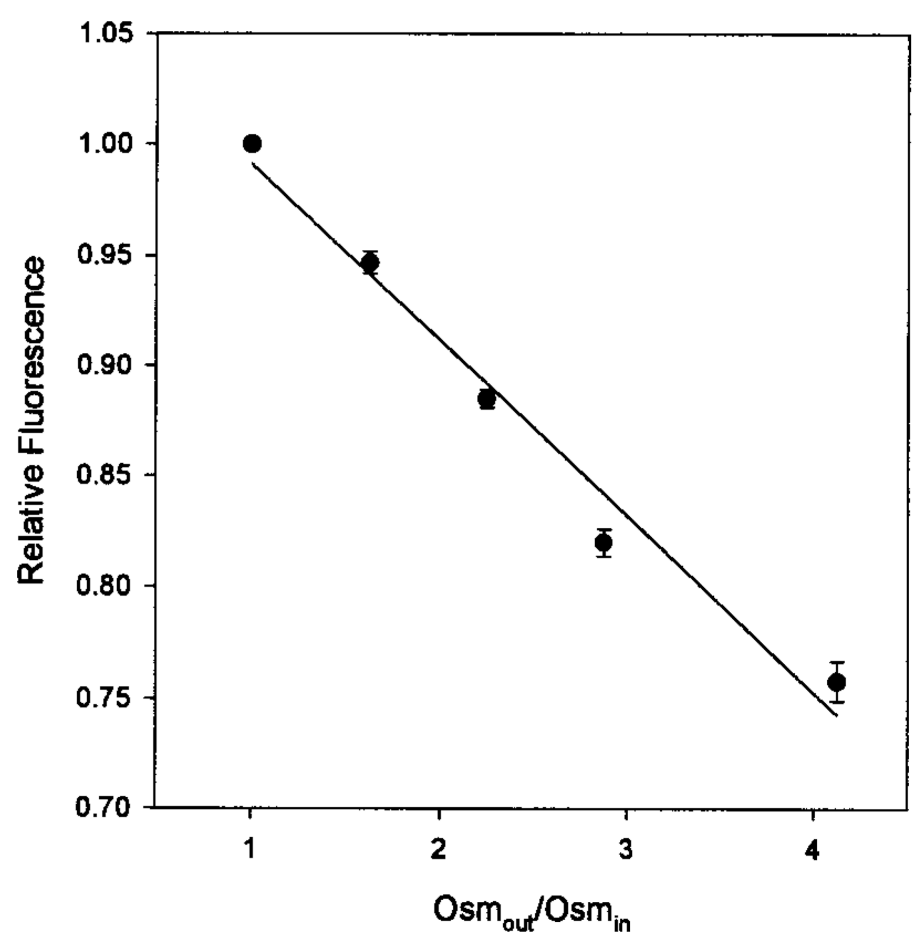

B

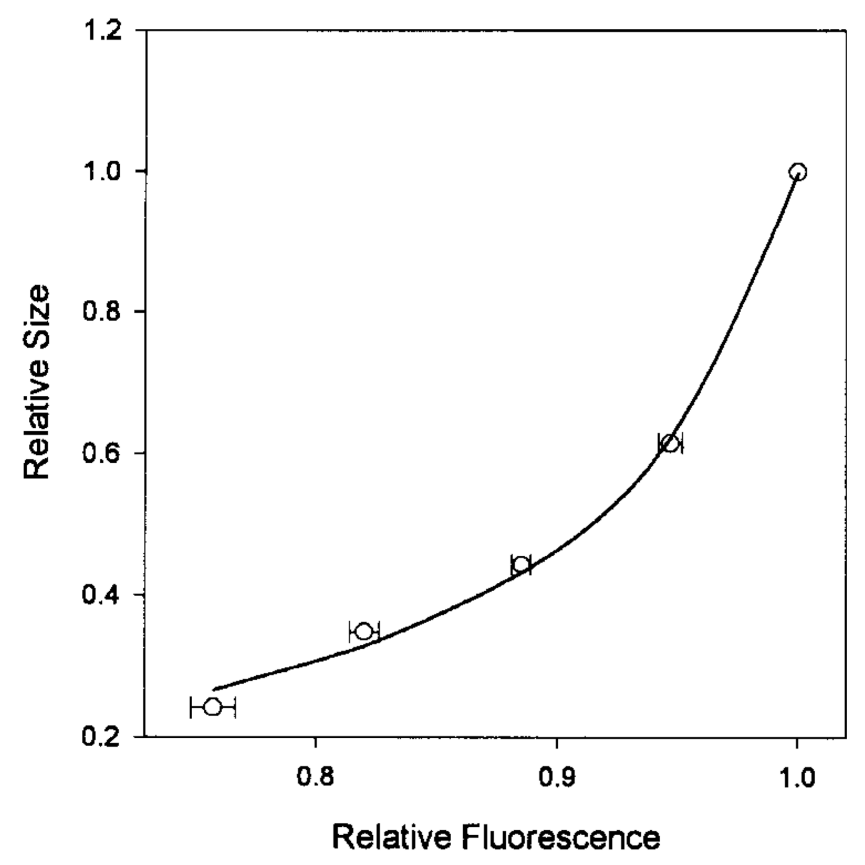

Fig. 3.

(A) The asymptote of the exponential fit was plotted against the ratio of the solution osmalities. The linear fit suggested an inverse relation between fluorescence and relative size. $(B)$ The asymptotes from the exponential fits are shown plotted against the relative size (assuming the vesicles to be perfect osmometers). The open circles represent the actual data and the line shows the fit equation. 


\section{Adult and Neonatal BBMV}

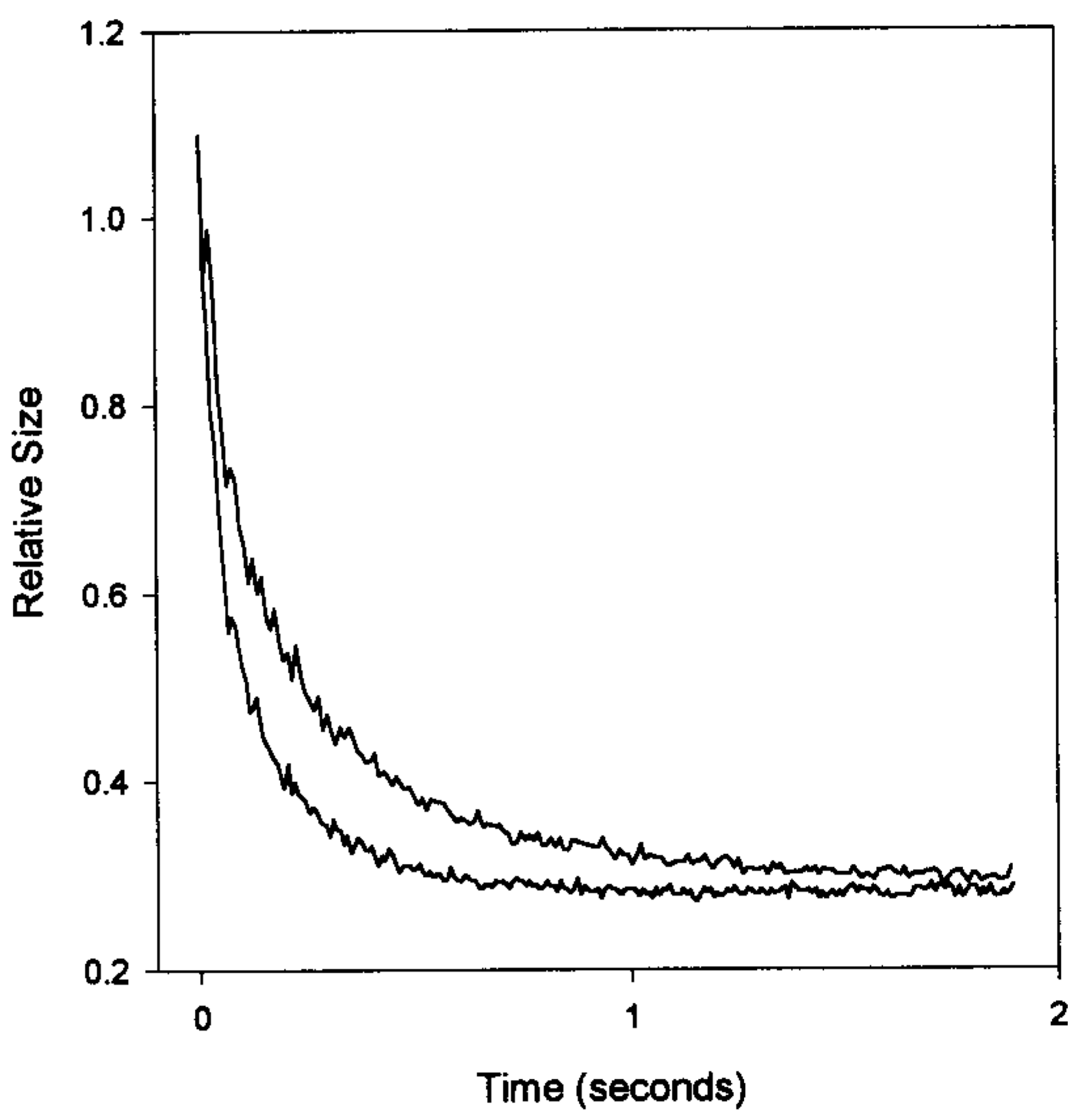

Fig. 4.

These curves show the same data from Fig. 2 after the relative fluorescence data has been transformed to relative size data using the transformation in Fig. $3 b$. The upper curve is the neonatal BBMV and the lower curve is the adult BBMV. 

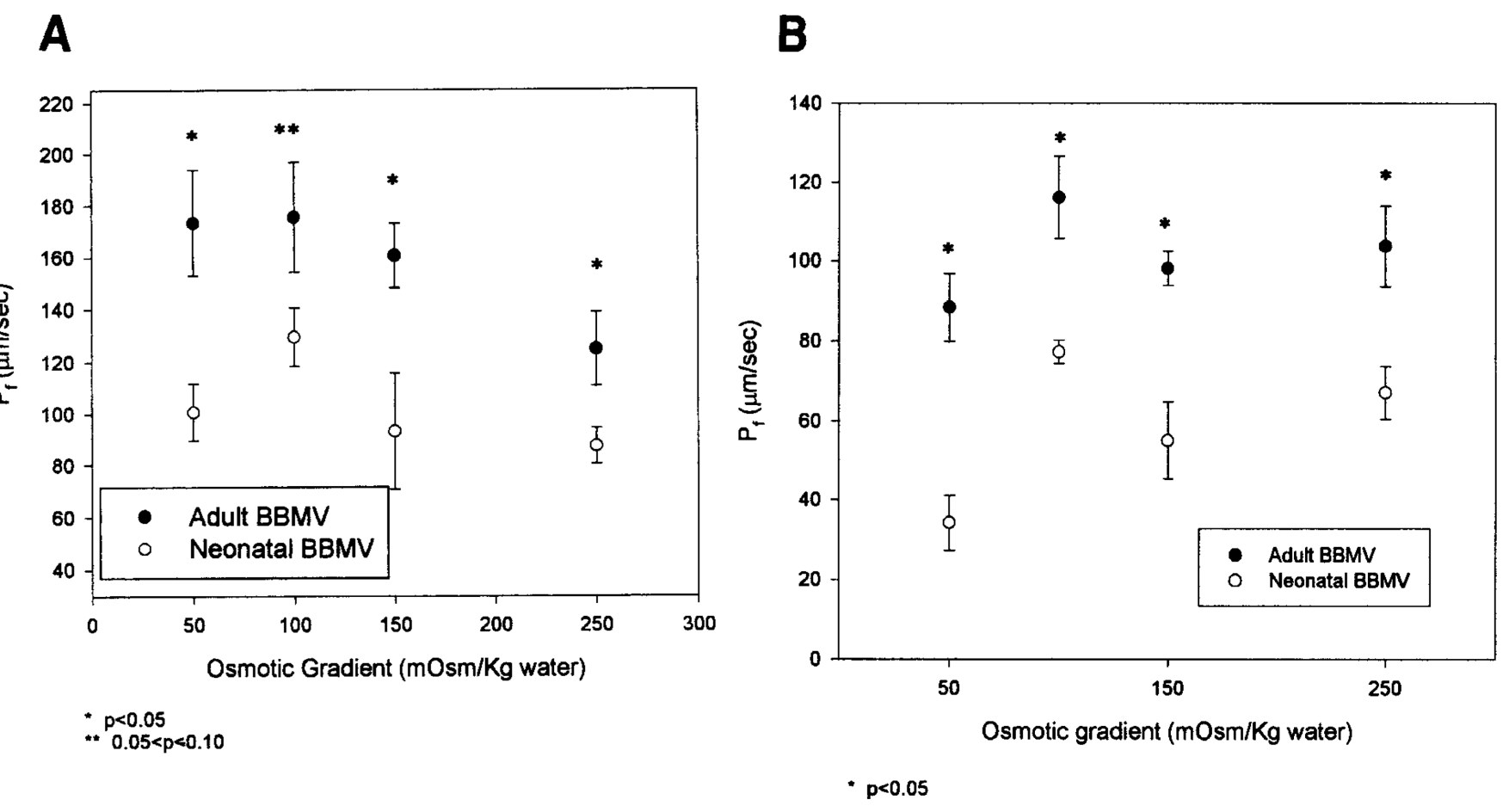

Fig. 5.

$\mathrm{P}_{f}$ of adult and neonatal BBMV. (A) $\mathrm{P}_{f}$ was determined from a double exponential curve. $(B)$ These values were obtained from fitting the relative size curves to second order kinetics. At all osmotic gradients tested, the $\mathrm{P}_{f}$ of neonatal BBMV was significantly lower than adult BBMV. 


\section{Activation Energies for Adult and Neonatal BBMV $\mathbf{P}_{\mathbf{f}}$}

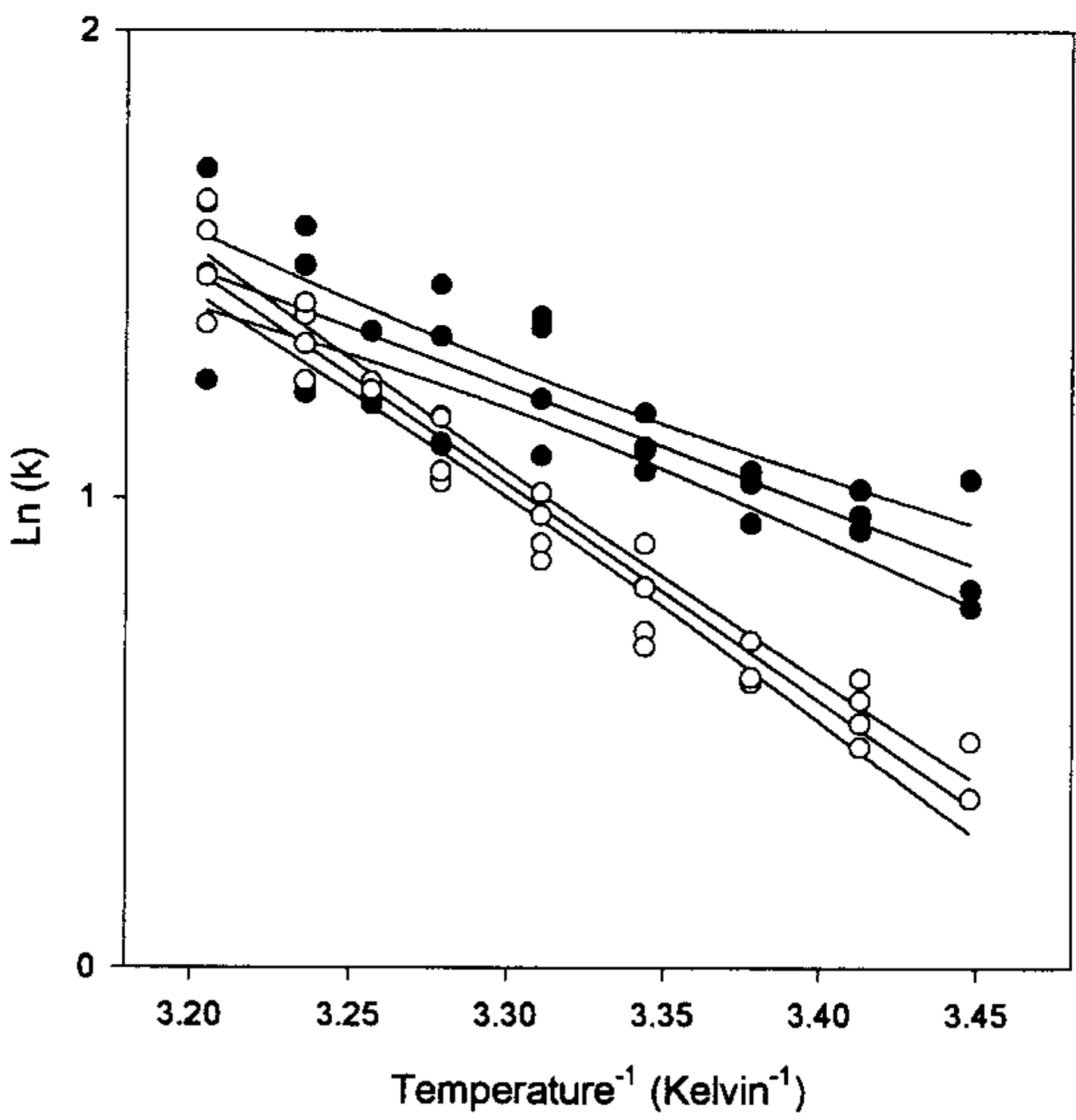

Fig. 6.

Arrhenius plots of temperature dependence of rate constants from the raw fluorescence data. Vesicles were loaded with $10 \mathrm{~m}$ fluorescein-sulfonate in resuspension buffer $(80 \mathrm{mOsm} / \mathrm{kg}$ water) and exposed to an inwardly directed osmotic gradient (150 mOsm/ $\mathrm{kg}$ water).

Temperature was varied from 17 to $39^{\circ} \mathrm{C}$. Activation energy, calculated from the slopes of the plots, was $9.19 \pm 0.37 \mathrm{kcal} \cdot \mathrm{deg}^{-1} \bullet \mathrm{mol}^{-1}$ for the neonatal BBMV (open circles) and $5.09 \pm 0.57 \mathrm{kcal} \bullet \mathrm{deg}^{-1} \cdot \mathrm{mol}^{-1}$ for the adult BBMV (closed circles) $(P<0.005)$. 

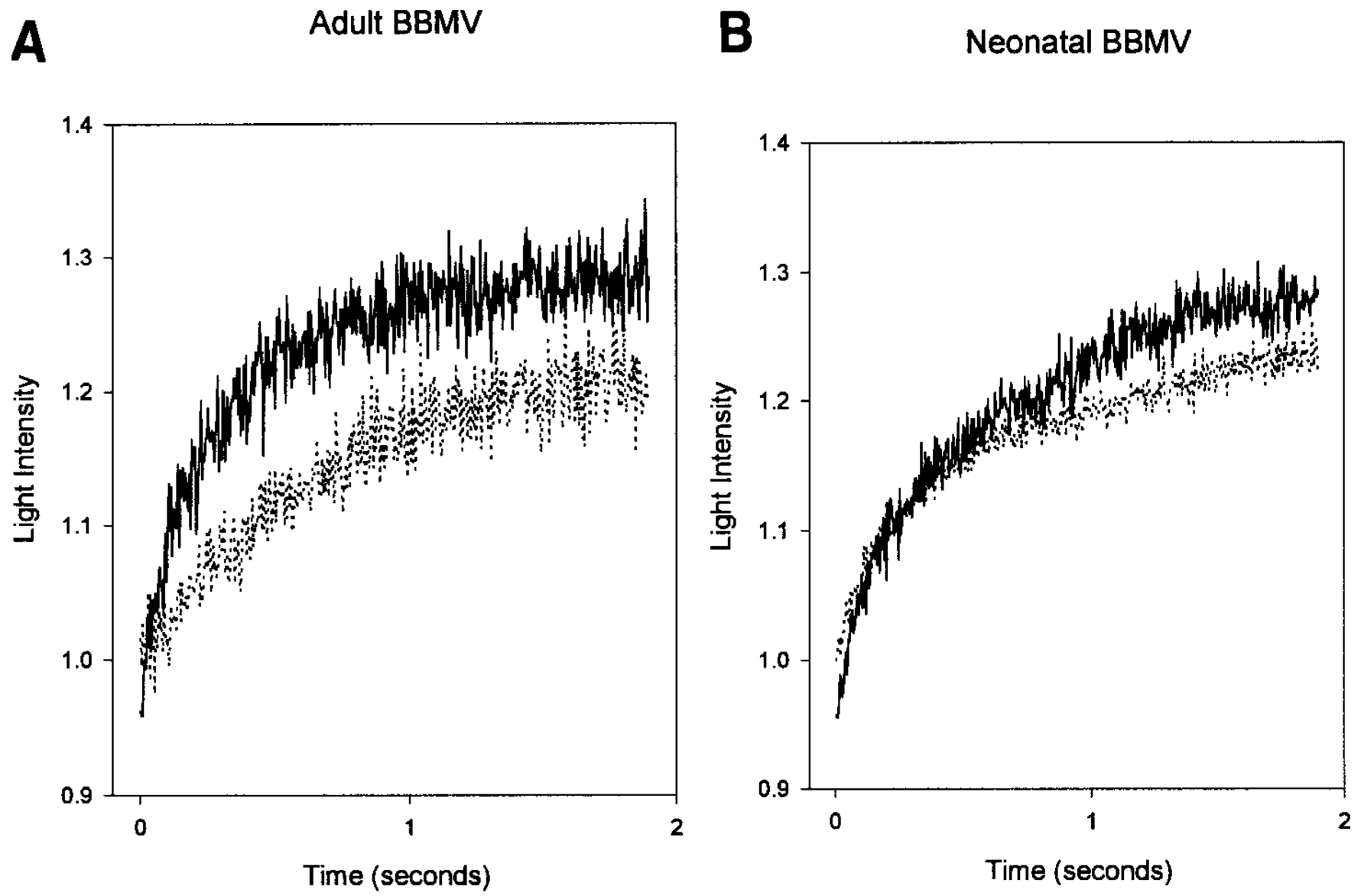

Fig. 7.

Effect of $1 \mathrm{~m}_{\mathrm{M}} \mathrm{HgCl}_{2}$ on osmotic water permeability was determined using light scattering for neonatal $(B)$ and adult $(A)$ BBMV. The lower curves in each panel are after treatment with $1 \mathrm{~m}_{\mathrm{M}} \mathrm{HgCl}_{2}$. 
